\title{
Dimensionless formulation for human stability in open flows
}

\section{Equacionamento adimensional para análise da instabilidade de humanos em escoamentos}

\author{
André Luiz Andrade Simões ${ }^{1}$, Harry Edmar Schulz ${ }^{2}$ and Lafayette Dantas da Luz ${ }^{1}$ \\ ${ }^{1}$ Universidade Federal da Bahia, Salvador, BA, Brasil \\ ${ }^{2}$ Escola de Engenharia de São Carlos, Universidade de São Paulo, São Carlos, SP, Brasil \\ E-mails: andre.simoes@ufba.br (ALAS),heschulz@sc.usp.br (HES),1luz@ufba.br (LDL)
}

Received: February 02, 2016 - Revised: April 18, 2016 - Accepted: June 08, 2016

\begin{abstract}
The stability of humans partially immersed in risky open water flows, resulting from urban flooding caused for example by dam breaks, or failures in drainage systems, or natural extreme events, is a topic of increasing interest because it involves the human safety in an environment that is more and more subjected to extreme events of hydraulic nature. The studies in this field of the applied fluid mechanics generally present equations that handle the results through dimensional quantities. These results were generally obtained in specific experiments for the evaluation of the stability of models of the human body. Intending to advance in the direction of a more general formulation, a dimensional analysis for the problem of human stability in open flows is presented here, showing dimensionless groups that represent the mentioned problem. Equations using these nondimensional groups were then developed using statistical analyses and approximations based on principles of physics and on data of the human body. The results obtained with the proposed methodology are of very good quality, presenting high correlation coefficients and good agreement between measured and calculated data.
\end{abstract}

Keywords: Dimensional analysis; Stability of the human body; Dimensionless formulation; Floods.

\section{RESUMO}

A estabilidade de humanos imersos em escoamentos superficiais por exemplo resultantes de inundações urbanas provocadas por ruptura de barragens, falhas em sistemas de drenagem ou eventos extremos é um tema de elevado interesse quando se trata de segurança humana e hidráulica de eventos extremos. Os trabalhos propostos neste campo apresentam seus resultados através de grandezas dimensionais, resultados de origem experimental ou formulações aproximadas para avaliação da estabilidade de modelos para o corpo humano. Aqui é apresentada uma análise dimensional que mostra a obtenção dos grupos adimensionais que representam o referido problema. Formulações em termos desses grupos adimensionais foram então desenvolvidas com análise estatística e aproximações fundamentadas em princípios físicos e dados do corpo humano. Destaca-se a boa qualidade dos resultados obtidos com a metodologia proposta, baseada em adimensionais, com elevados coeficientes de correlação e boa concordância entre dados medidos e calculados.

Palavras-chave: Análise dimensional; Estabilidade do corpo humano; Formulação adimensional; Inundações. 


\section{INTRODUCTION}

Free surface flows occurring around partially submerged human beings can result in instabilities and fall, the drag of the human beings, and serious injuries. Urban floods that occur due to extrapolations of the capacity of drainage systems, or the traveling of flood waves of dam breaks or extreme events are examples that illustrate the direct interaction between human beings and the kind of flow mentioned.

The quantification of the sort of instabilities mentioned in the previous paragraph has as its basic purpose the preservation of life and health of people that may be at risk in unusual flows. Such modeling must thus be based on the knowledge of mechanics and biology. Studies of free surface flows around obstacles may be dated back to the fifteenth and sixteenth centuries, when Leonardo da Vinci (1452-1519) has drawn details of such external flows, as illustrated in Figure 1. In his sketches it is possible to observe the elevation of the free surface at the stagnation region, and downstream vortex streets with the today known low pressure zones. The combined effect of the efforts due to the described flow pattern may cause oscillations or even may overturn the obstacle. However, there are additional effects that are not so apparent on general observations like the Leonardo's drawings. For example, in a preliminary assessment of the stability of a submerged object, it is considered important to include the shear on the surface of the object into contact with the fluid, and the friction between its lower surface and the bottom of the channel. The complexity of the problem is increased when human biology is added as a relevant factor. Although this difficulty is readily recognized in analytical approaches, it is considered reasonable to establish the following general destabilization criteria:

\section{Shear destabilization at the bottom surface:}

The drag force exceeds the static friction force along the bottom surface. The static friction force depends on the force applied perpendicularly to the bottom surface (weight) and on the rheological characteristics of the sludge supporting the human

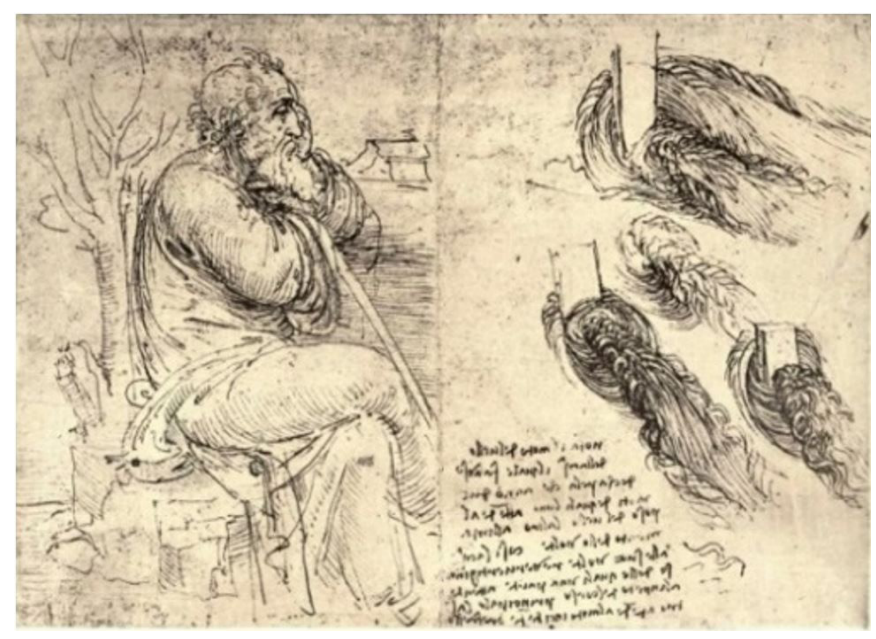

Figure 1. Leonardo da Vinci's drawing of turbulent free surface flows around obstacles. Richter (1883, Part I, p. 200). being (or the roughness of the bottom, if there is no sludge). This is recognized as the condition for the occurrence of slippage.

\section{Destabilization through impact:}

The drag force is mainly quantified as proportional to $\rho \mathrm{V}^{2} \mathrm{~A}$, establishing a strong influence of the flow velocity, but also involving the blocking area. It can be different for individuals facing the flow and for individuals with its flank turned to the flow (that is, frontal or lateral impacts, respectively). The area of the impact region thus varies. A person can be simply overturned.

\section{Destabilization by vortex shedding oscillation:}

In this case, the geometric and dynamic conditions enable the formation of vortexes downstream of the person (this phenomenon is usually related to the Reynolds number and not to the Froude number). While the person is balancing for a vortex with a force component in one direction, the following vortex reverses the direction and impairs the balance, which may cause the fall of the person.

\section{Instability due to suspension:}

A person in a flow may think that, to avoid its own fall, can hunker down with its back impacting the flow, possibly also leaning on its hands while trying to improve links with the background. In this condition, if a wave or a rise in the water level occur, the person may be suspended due to pressure effects (such as sediment saltation - lower pressures on the upper part of the sediments).

As can be seen, these criteria involve different causes for destabilization, allowing reasoning about the physics of stability for human beings in risky flows.

Abt et al. (1989) presented one of the first systematic studies related to the stability of human beings subjected to the action of risky flows. The mentioned authors conducted experiments in a rectangular channel with bottom slopes of 0.005 and 0.015 , $2.44 \mathrm{~m}$ wide, $61 \mathrm{~m}$ long and $1.22 \mathrm{~m}$ deep. The maximum flow rate employed in the tests was about $2.83 \mathrm{~m}^{3} / \mathrm{s}$. Twenty individuals with age between 19 and 54 participated in the tests. They had good health, heights between 152 and $183 \mathrm{~cm}$ and masses between 40.9 and $91.4 \mathrm{~kg}$ (ABT et al., 1989, p. 883). The authors point out that similar clothes were used, composed by jeans, sweater, and sneakers or boots. The authors analyzed the results of the experimental study and furnished Equation 1.

$\mathrm{hV}=\exp \left[0.222\left(\frac{\mathrm{wt} \times \mathrm{ht}}{1000}\right)+1.088\right]$

$\mathrm{h}[\mathrm{ft}]$ is the flow depth, $\mathrm{V}[\mathrm{ft} / \mathrm{s}]$ is the mean flow velocity; wt is weight in pounds; and ht is the height in inches (of the individuals). According to the authors, the equation has $R^{2}=0.48(R=0.6928)$, where $\mathrm{R}$ is the correlation coefficient. It is observed that the model does not include the roughness of the surface and other parameters of the channel, and does not address the characteristics of the persons. Also no questions were presented about the flow conditions, for example if it is gradually varied or uniform.

Karvonen et al. (2000) also conducted tests with human beings, using seven individuals with ages between 17 and 60, in a channel $130 \mathrm{~m}$ long and $11 \mathrm{~m}$ wide. Jonkman and Penning-Rowsell (2008) later analyzed the data from Abt et al. (1989) and Karvonen et al. 
(2000). The author proposed a block as a model for the human body and furnished a subsequent mathematical formulation considering the sum of forces (translational instability), the sum of moments (rotational instability), and the combination of both effects.

Xia et al. (2014) conducted experiments in reduced scale using a physical model (a doll with similar garments than that of a soldier) $0.3 \mathrm{~m}$ height and a mass of $0.334 \mathrm{~kg}$. The model was positioned frontally and backwards to the flow direction. The authors modeled the problem according to the Newtonian mechanics considering destabilization mechanisms of sliding and tipping. Similarly, Rotava (2014) and Milanesi et al. (2015) suggested formulations based on summation of forces and moments for the condition of imminent movement Chanson et al. (2015), in a discussion linked to the work of Xia et al. (2014), mentioned that turbulence, velocity fluctuations, and flow depths are intervening factors that were not adequately represented by the small-scale model. As general characteristics, the aforementioned literature presents experimental results and proposes mathematical models represented accordingly the original dimensions of the used variables. The purpose of the present article is to review the previous information following a point of view employing dimensionless variables. Anon-dimensional formulation is aimed, intending to extend the results of the literature to eventual more general uses.

\section{METHODOLOGY}

The studies described in the preceding paragraphs and the analysis of the problem addressed here led to the identification of the more relevant dimensional quantities linked to the study of human stability in flows (please see Figure 2 for the understanding of the involved forces) and to the proposition of Equation 2.

$\mathrm{F}\left(\rho, \mu, \mathrm{g}, \mathrm{V}, \mathrm{h}, \mathrm{F}_{1}, \mathrm{~F}_{2}, \mathrm{~F}_{3}, \mathrm{~d}_{1}, \ldots\right.$

$\left.\ldots \mathrm{d}_{2}, \mathrm{~d}_{3}, \varepsilon, \mathrm{I}_{\mathrm{o}}, \mathrm{H}_{\mathrm{h}}, \mathrm{M}_{\mathrm{h}}, \mathrm{I}, \mathrm{FH}\right)=0$,

where $\rho=$ density of the liquid; $\mu=$ dynamic viscosity; $\mathrm{g}=$ acceleration of gravity; $\mathrm{V}=$ average flow velocity not disturbed by the obstacle; $\mathrm{h}$ = flow height not disturbed by the obstacle; $\mathrm{d}_{1}=$ vertical distance between the point of application of the weight of the obstacle and its supporting point; $\mathrm{d}_{2}=$ vertical distance between the line passing through the application point of $\mathrm{F}_{2}$ and the supporting point; $\mathrm{d}_{3}=$ characteristic distance between legs; $H_{h}=$ obstacle height, $\varepsilon=$ roughness of the solid surface; $\mathrm{I}_{\mathrm{o}}=$ bottom slope; $\mathrm{M}_{\mathrm{h}}=$ mass of the obstacle; $\mathrm{I}=$ age of the individual; $\mathrm{FH}=$ dimensionless factor related to health

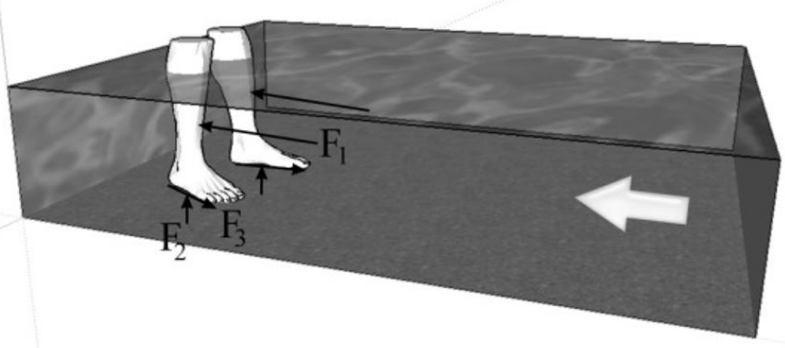

Figure 2. Forces on part of the human body. and momentary psychological factors. The insertion of FH as a relevant variable is justified by the existence of variations in the level of knowledge of different individuals, knowledge built for example by personal experiences, specific training for survival in adverse conditions, among others. There is a natural relationship between age, physical ability and level of knowledge.

The forces on the submerged surface of the human body are illustrated in Figure 2 and defined as: $\mathrm{F}_{1}$ force due to the pressure distribution and shear stresses caused by the fluid; $\mathrm{F}_{2}=$ vertical force on the bottom of the foot or shoe and $F_{3}=$ force due to the friction with the ground.

The dimensionless parameters were defined by applying the theorem of Vaschy-Buckingham, using the pro-basic system formed by $\rho, \mathrm{V}$ and h, resulting in Equation 3.

$$
\begin{aligned}
& \Phi\left(\operatorname{Re}, \mathrm{Fr}, \mathrm{C}_{1}, \mathrm{C}_{2}, \mathrm{C}_{3}, \frac{\mathrm{d}_{1}}{\mathrm{~h}}, \frac{\mathrm{d}_{2}}{\mathrm{~h}}, \ldots\right. \\
& \left.\ldots \frac{\mathrm{d}_{3}}{\mathrm{~h}}, \frac{\mathrm{H}_{\mathrm{h}}}{\mathrm{h}}, \frac{\varepsilon}{\mathrm{h}}, \mathrm{I}_{\mathrm{o}}, \frac{\mathrm{M}_{\mathrm{h}}}{\mathrm{\rho h}^{3}}, \frac{\mathrm{VI}}{\mathrm{h}}, \mathrm{FH}\right)=0,
\end{aligned}
$$

where $\operatorname{Re}=\rho \mathrm{Vh} / \mu$ (Reynolds Number); Fr $=\mathrm{V} /(\mathrm{gh})^{1 / 2}($ Froude Number); $\mathrm{C}_{\mathrm{i}}=\mathrm{F}_{\mathrm{i}} /\left(0.5 \rho \mathrm{V}^{2} \mathrm{~h}^{2}\right)$, with $\mathrm{i}=1,2,3$.

\section{Model based on data from Abt et al. (1989)}

The data published by Abt et al. (1989) enabled to study the relationship between some of the dimensionless parameters present in Equation 3, explicitly shown in Equation 4.

$$
\mathrm{M}^{*}=\Phi_{2}\left(\operatorname{Re}, \mathrm{Fr}, \mathrm{H}^{*}, \frac{\varepsilon}{\mathrm{h}}, \mathrm{I}_{\mathrm{o}}, \mathrm{I}^{*}\right)
$$

where $\mathrm{M}^{*}=\frac{\mathrm{M}_{\mathrm{h}}}{\mathrm{\rho h}^{3}}, \mathrm{H}^{*}=\frac{\mathrm{H}_{\mathrm{h}}}{\mathrm{h}}$ e I* $=\frac{\mathrm{VI}}{\mathrm{h}}$.

It should be emphasized that all data correspond to critical values, i.e. the values of the dimensionless parameters were calculated using the data corresponding to the unstable condition of the people who participated in the experiments.

\section{RESULTS AND DISCUSSION}

The first step consisted here in seeking more clear links between pairs of dimensionless parameters, that is, in looking for the most evident correlations between pairs of variables. Further, as second step, these primary relationships were used as a basis for correlations using three or more dimensionless parameters. The graphs of Figure 3 summarize the initial exploratory test. It is observed, for instance, that $\mathrm{M}^{*}$ has virtually no correlation with Re. However, the figure also shows that there are positive correlations between other pair of variables, allowing inferring approximately linear or power laws behaviors. Although correlations with the dimensionless parameter that involves the roughness of the bottom were performed in the present sutdy, the absolute experimental roughnesses were not informed by Abt et al. (1989). The equivalent roughnesses were estimated based on the materials described by the authors, namely, concrete $(0.00085 \mathrm{~m})$, grass $(0.06938 \mathrm{~m})$, gravel $(0.522 \mathrm{~m})$, and steel $(0.0004 \mathrm{~m})$ (PORTO, 2006, p. 49, 246, 273-274). 
Figure 3 allowed performing empirical exploratory analyses using $\Phi_{2}$ (see Equation 4 ) as the product of powers of six dimensionless parameters:

$$
\mathrm{M}^{*}=\mathrm{c}_{1} \operatorname{Re}^{\mathrm{c}_{2}} \mathrm{Fr}^{\mathrm{c}_{3}} \mathrm{H}^{* \mathrm{c}_{4}}\left(\frac{\varepsilon}{\mathrm{h}}\right)^{\mathrm{c}_{5}} \mathrm{I}_{\mathrm{o}}^{\mathrm{c}_{6}} \mathrm{I}^{\mathrm{c}_{7}}
$$

where $\mathrm{c}_{1}, \mathrm{c}_{2}, \mathrm{c}_{3}, \mathrm{c}_{4}, \mathrm{c}_{5}, \mathrm{c}_{6}$ and $\mathrm{c}_{7}$ are constant dimensionless numeric values to be adjusted. Applying a nonlinear regression to the data of Abt et al. (1989) produced the values for $\mathrm{c}_{1}$ to $\mathrm{c}_{7}$ presented in Table 1.
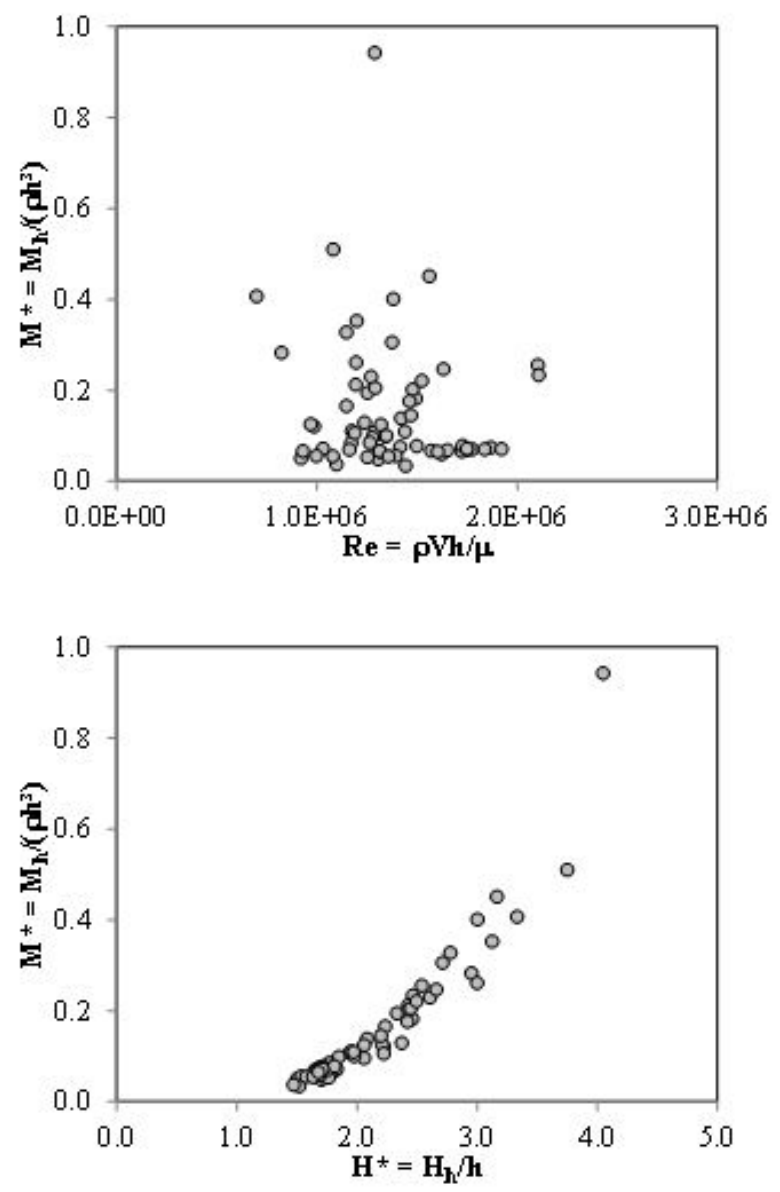

(a)

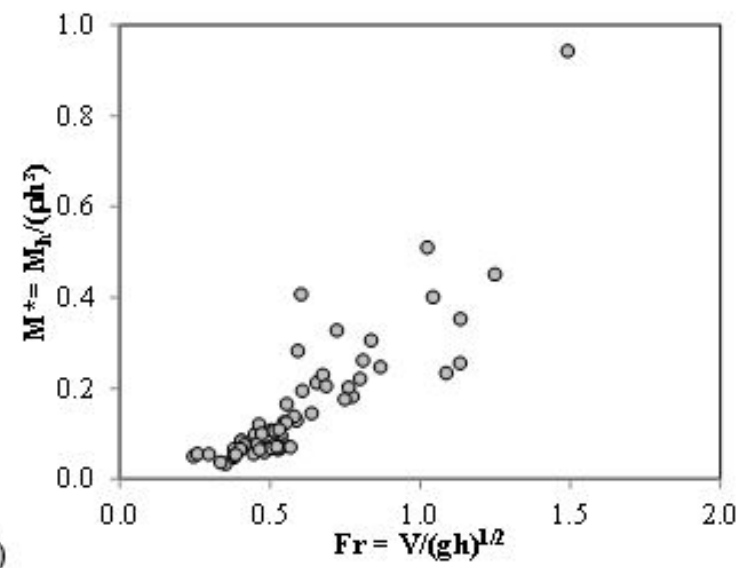

(b)

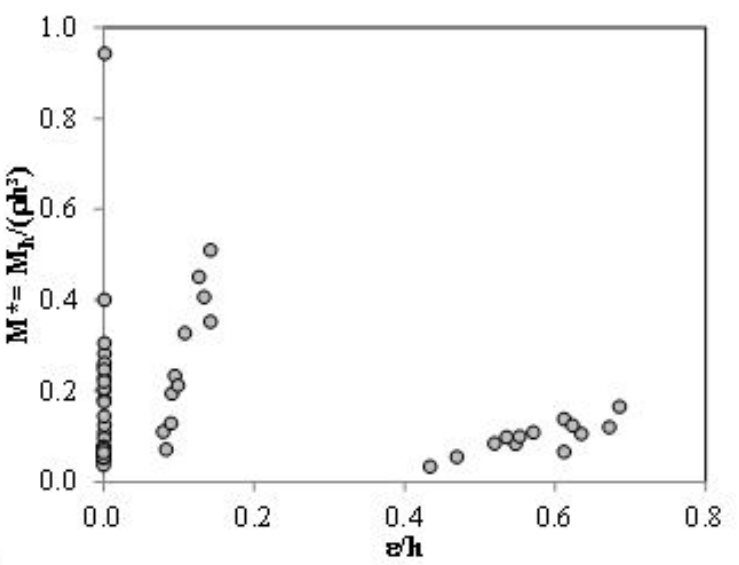

(c)

Table 1. Parameters of Equation 5 calculated with data of Abt et al. (1989).

\begin{tabular}{ccccccc}
\hline $\mathbf{c}_{1}$ & $\mathbf{c}_{2}$ & $\mathbf{c}_{3}$ & $\mathbf{c}_{4}$ & $\mathbf{c}_{5}$ & $\mathbf{c}_{6}$ & $\mathbf{c}_{7}$ \\
\hline $3.189 \mathrm{E}-06$ & -1.017 & 0.00118 & 0.00115 & -0.0208 & 0.275 & 1.226 \\
\hline
\end{tabular}

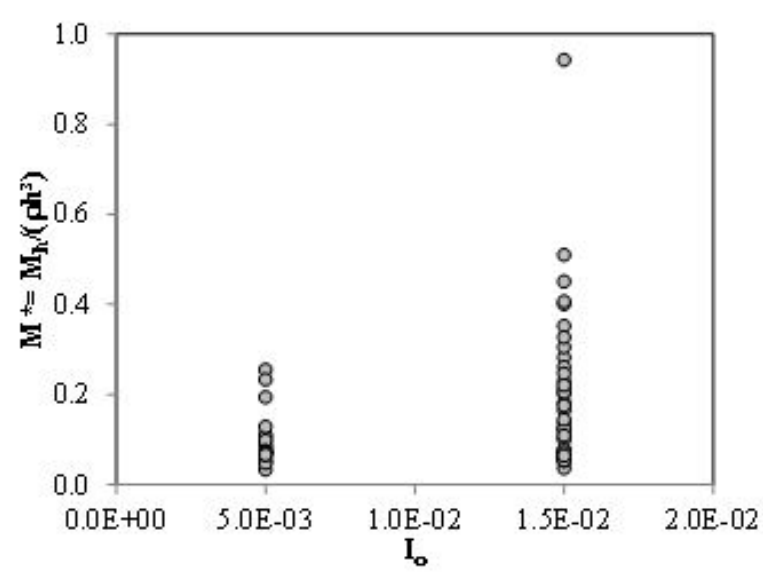

(e)

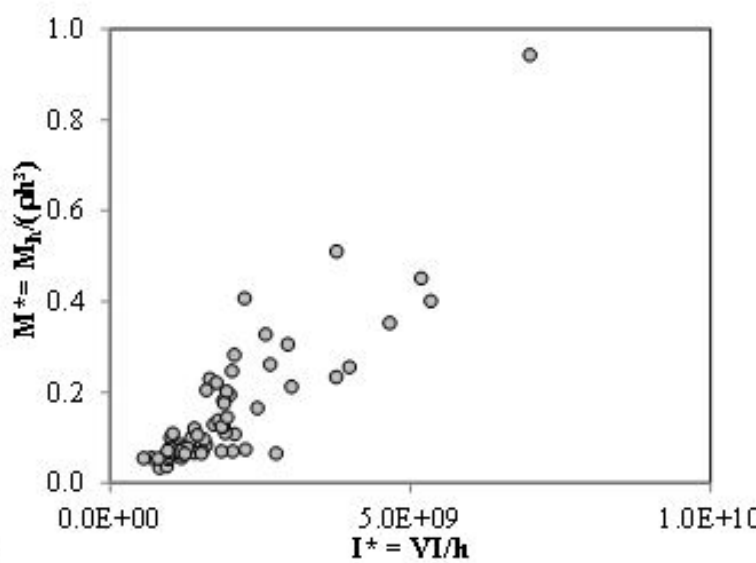

(f)

Figure 3. Observed correlations between pairs of variables. Definitions: $\varrho=$ density of the liquid; $\mu=$ dynamic viscosity; $\mathrm{g}=$ acceleration of gravity; $\mathrm{V}$ = average flow velocity not disturbed by the obstacle; $\mathrm{h}=$ flow height not disturbed by the obstacle; Hh = obstacle height, $\varepsilon=$ roughness of the solid surface; $\mathrm{Io}=$ bottom slope; $\mathrm{Mh}=$ mass of the obstacle; $\mathrm{I}=$ age of the individual. The correlation coefficients between $\mathrm{M}^{*}$ and the dimensionless parameters of graphs $3 \mathrm{a}-\mathrm{f}$, are, respectively: $0.1266 ; 0.86522 ; 0.93485 ; 0.1093 ; 0.29059 ; 0.8696$. 
in Figure 4a, together with the respective distributions of points of $\mathrm{M}^{*}$ along the two axes. Figure $4 \mathrm{~b}$ shows the distribution of residuals relative to the standard distribution of residuals. A reasonable good adjustment in relation to the Normal
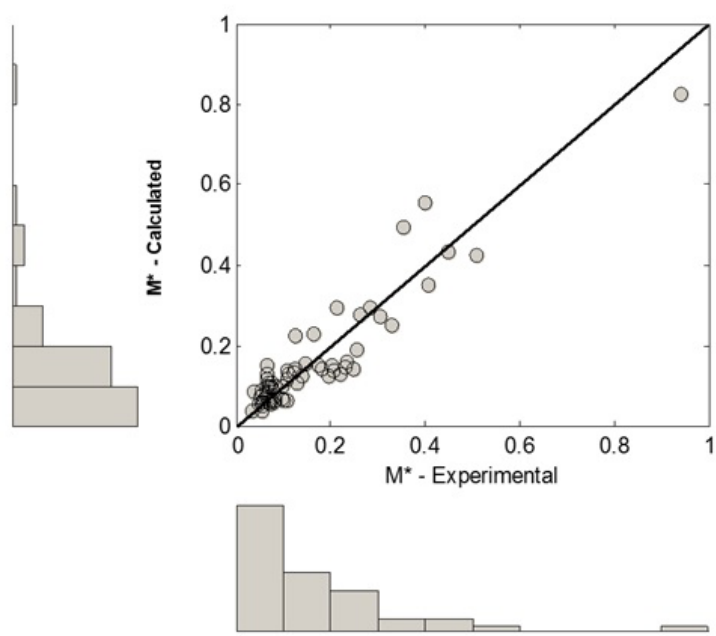

(a)
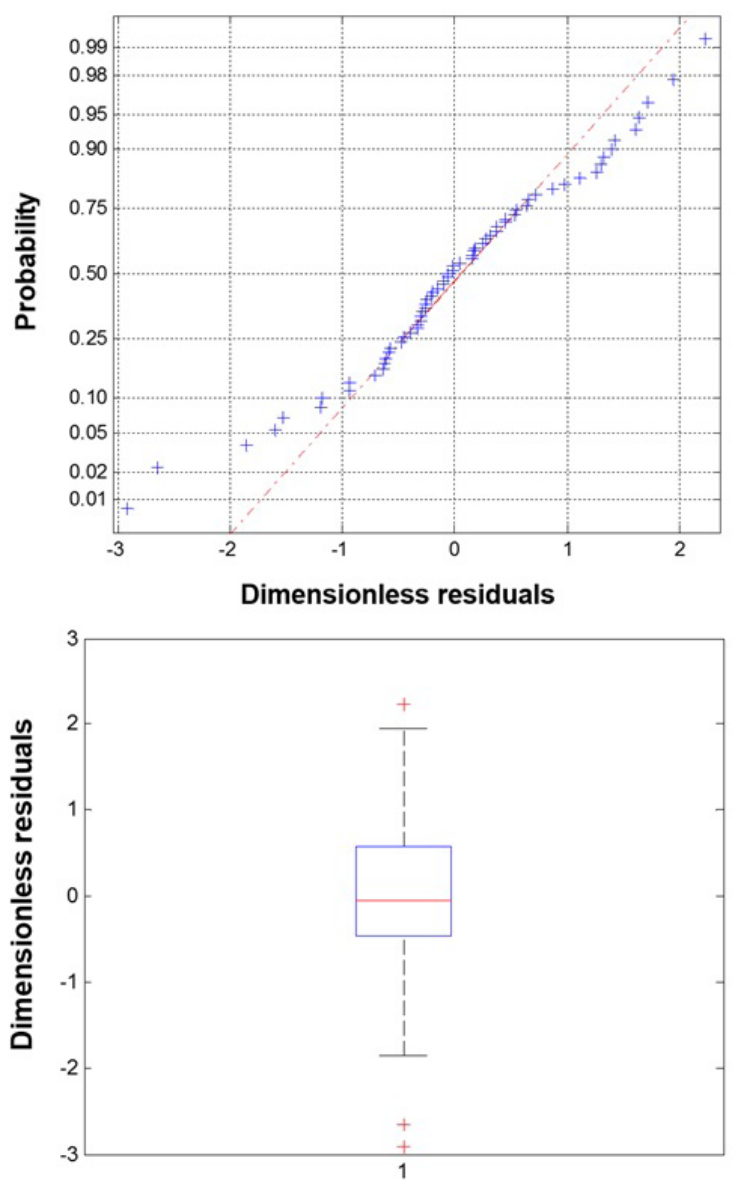

(b)

(c)

Figure 4. Analysis of Equation 5 using the values given in Table 1. Definitions: $\mathrm{M}^{*}=\mathrm{Mh} /\left(\mathrm{ph}^{3}\right)$, dimensionless parameter; dimensionless residuals $=\left(\mathrm{M}^{*} \mathrm{e}-\mathrm{M}^{*} \mathrm{c}\right) / \mathrm{p}, \mathrm{M}^{*} \mathrm{e}=$ experimental data, $\mathrm{M}^{*} \mathrm{c}=$ calculated data, $\sigma=$ standard deviation. (a) Ideal line; (b) normal probability plot of the dimensionless residuals; (c) box plot for dimensionless residuals. distribution is observed. The chart of Figure 4c intends to show that outliers set to the statistical criterion of boxes diagram cannot retain this concept due to the nature of the problem, that includes the human factor.

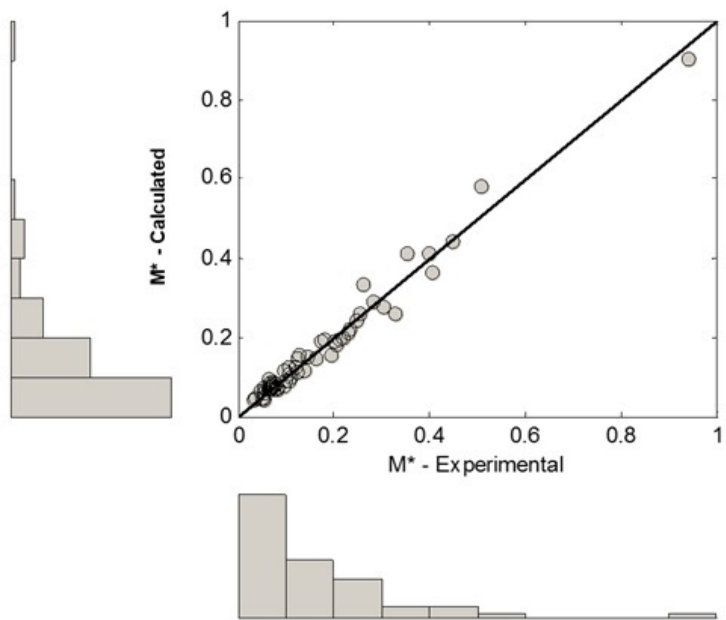

(a)

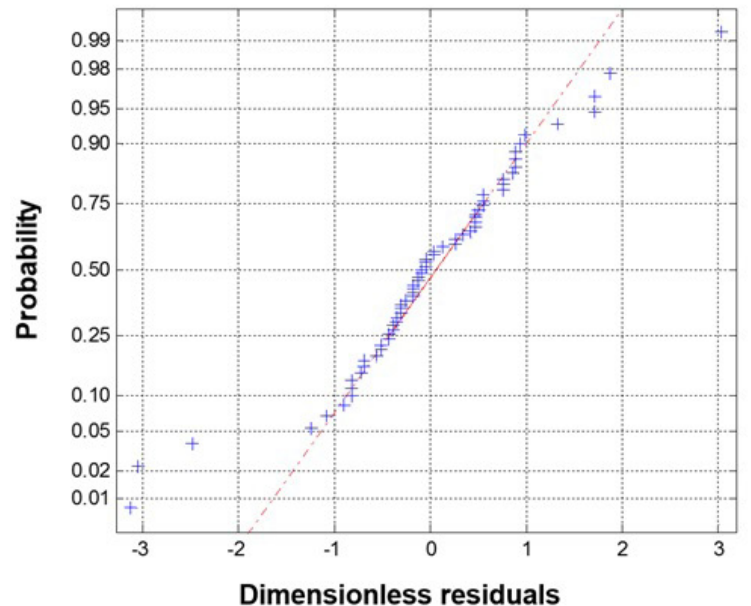

(b)

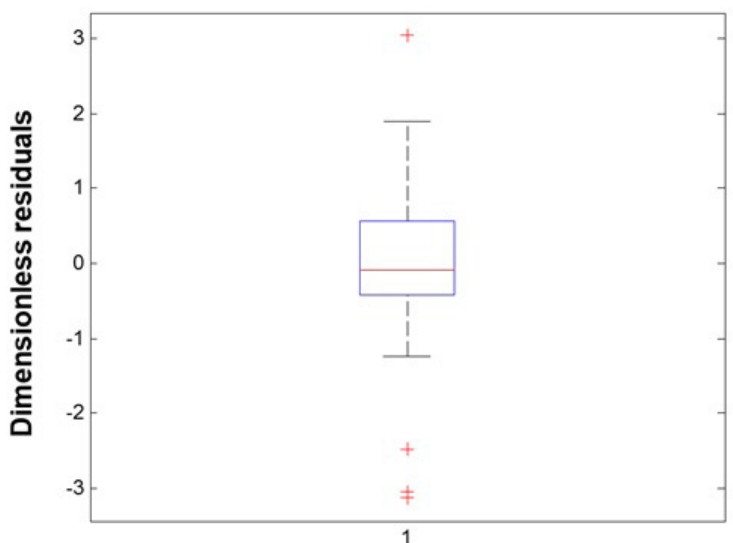

(c)

Figure 5. Analysis of Equation 5 using the values given in Table 2. Definitions: $\mathrm{M}^{*}=\mathrm{Mh} /\left(\mathrm{ph}^{3}\right)$, dimensionless parameter; dimensionless residuals $=\left(\mathrm{M}^{*} \mathrm{e}-\mathrm{M}^{*} \mathrm{c}\right) / \sigma, \mathrm{M}^{*} \mathrm{e}=$ experimental data, $\mathrm{M}^{*} \mathrm{c}=$ calculated data, $\sigma=$ standard deviation. (a) Ideal line; (b) normal probability plot of the dimensionless residuals; (c) box plot for dimensionless residuals. 
Table 2. Parameters for the Equation 5 (with $\mathrm{c}_{2}=0$ ).

\begin{tabular}{ccccccc}
\hline $\mathbf{c}_{1}$ & $\mathbf{c}_{2}$ & $\mathbf{c}_{3}$ & $\mathbf{c}_{4}$ & $\mathbf{c}_{5}$ & $\mathbf{c}_{6}$ & $\mathbf{c}_{7}$ \\
\hline $1.524 \mathrm{E}-04$ & 0 & 0.1447 & 2.262 & -0.0151 & 0.0282 & 0.2422 \\
\hline
\end{tabular}

\section{Model with $c_{2}=0\left(\operatorname{Re}^{0}=1\right)$}

The previous comment of the possible independence between $\mathrm{M}^{*}$ and the Reynolds number shown in Figure 3 a suggested the exclusion of Re from the original model, generating a new function (Equation 5 with the new parameters of Table 2) with a correlation coefficient $\mathrm{R}=0.98739$ (see Figure 5). It is known that $\mathrm{R}$ tends to increase with the addition of variables to a model, being an insufficient measure of the quality of the desired adjustment (if considered as the only criterion). However, in the present case $\mathrm{R}$ increases when excluding $\mathrm{Re}$, a condition that reinforces the idea of the independence between $\mathrm{M} *$ and Re. This fact is presented here for the set of analyzed data, not being found in literature texts. It is worth noting that the Reynolds number in question is the one linked to the water depth. For other analyses, like the vortex shedding, the Reynolds number considers the obstacle diameter, being necessary to have information of leg and stem diameters of the individuals involved in the tests. These information were not provided by the consulted texts. In addition, also instability due to suspension was not considered in this analysis.

\section{Model with $\mathrm{c}_{2}=0$ and $\mathrm{c}_{7}=0$ (exclusion of Re and $\left.I^{*}\right)$}

Without the knowledge of $\mathrm{FH}$, the influence of the dimensionless parameter $I^{*}$ may be ambiguous, because an increase of $\mathrm{I}^{*}$ by increasing I (age) can be either unfavorable or favorable to stability. This eventual "two fold" trend was avoided here by imposing $\mathrm{c}_{7}=\mathrm{c}_{2}=0$ in Equation 5 , as shown in Table 3. The adjustment of the remaining coefficients resulted in a value of $\mathrm{R}=0.98508$ (see Figure 6), only slighter lower than the value obtained for Table 2 , suggesting that $\mathrm{I}^{*}$ does not represent a relevant variable for the present set of data.

\section{Inclusion of data from Karvonen et al. (2000)}

Therefore, the analyzed data set allowed to obtain a predictive equation quite adequate, expressed by Equation 5 and the coefficients furnished in Table 3. Considering that other experiments do not show the number of variables used here, some further simplifications were tested. Figure 3 shows that the bottom slope has little influence on the analyzed correlation, with changes of $0.8 \%$ and $0.6 \%$ in the average predictions for $\mathrm{I}=0.005$ and $I_{o}=0.015$, respectively. The same comparative procedure of including and excluding the relative roughness showed that its exclusion does not imply significant changes in the calculated values, although the exponent -0.0139 is not necessarily negligible. The two simplifications were applied here $\left(\mathrm{c}_{5}=\mathrm{c}_{6}=0\right)$ in order to insert the data of Karvonen et al. (2000) in this proposal. Equation 6 represents the solution obtained from the joint analysis of the data of Abt et al. (1989) and Karvonen et al. (2000), furnishing $\mathrm{R}=0.9916$ between measured and calculated data. The graphs in Figure 7 summarize the statistical analysis of these data.
Table 3. Parameters for the Equation $5\left(c_{2}=0\right.$ and $\left.c_{7}=0\right)$.

\begin{tabular}{ccccccc}
\hline $\mathbf{c}_{1}$ & $\mathbf{c}_{2}$ & $\mathbf{c}_{3}$ & $\mathbf{c}_{4}$ & $\mathbf{c}_{5}$ & $\mathbf{c}_{6}$ & $\mathbf{c}_{7}$ \\
\hline $2.500 \mathrm{E}-02$ & 0 & 0.442 & 2.366 & -0.0139 & -0.001512 & 0 \\
\hline
\end{tabular}

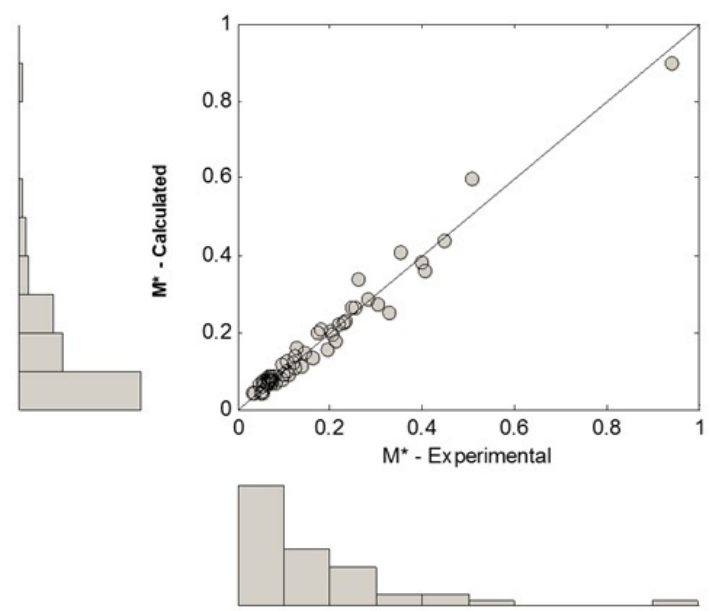

(a)

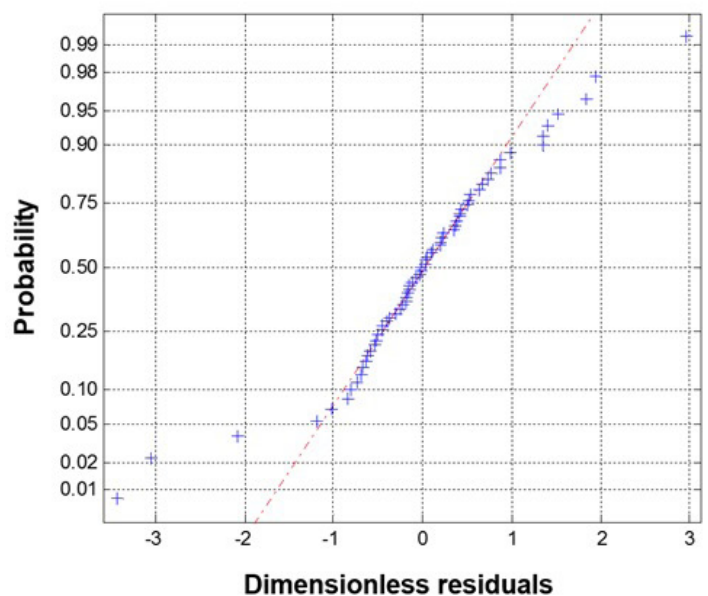

(b)

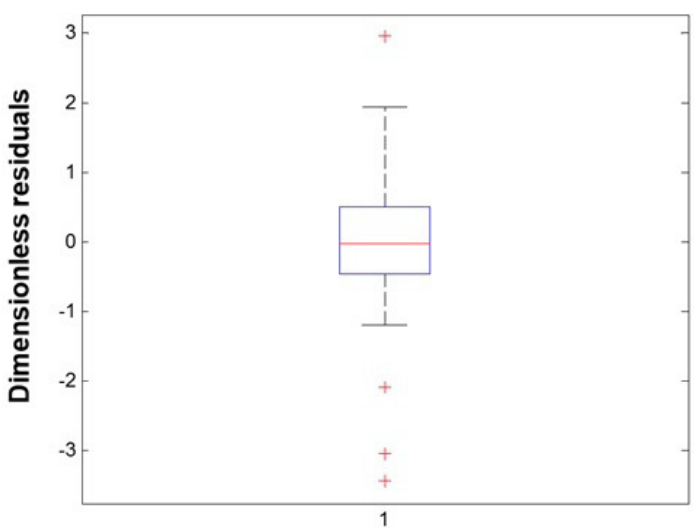

(c)

Figure 6. Analysis of Equation 5 using the values given in Table 3. Definitions: $\mathrm{M}^{*}=\mathrm{Mh} /\left(\mathrm{ph}^{3}\right)$, dimensionless parameter; dimensionless residuals $=\left(\mathrm{M}^{*} \mathrm{e}-\mathrm{M}^{*} \mathrm{c}\right) / \sigma, \mathrm{M}^{*} \mathrm{e}=$ experimental data, $\mathrm{M}^{*} \mathrm{c}=$ calculated data, $\sigma=$ standard deviation. (a) Ideal line; (b) normal probability plot of the dimensionless residuals; (c) box plot for dimensionless residuals. 
$\frac{\mathrm{M}_{\mathrm{h}}}{\mathrm{\rho h}^{3}}=0.01538 \mathrm{Fr}^{0.165}\left(\frac{\mathrm{H}_{\mathrm{h}}}{\mathrm{h}}\right)^{2.898}$

The equations is valid for $0.187 \leq \mathrm{Fr} \leq 1.491 ; 1.471 \leq \mathrm{H}^{*} \leq 4.887$. The experiments that resulted in the data used here included individuals facing frontally the flow and a gradual increase of the flow rates to prevent the formation of billows. The individuals were periodically asked about the conditions of stability. Details
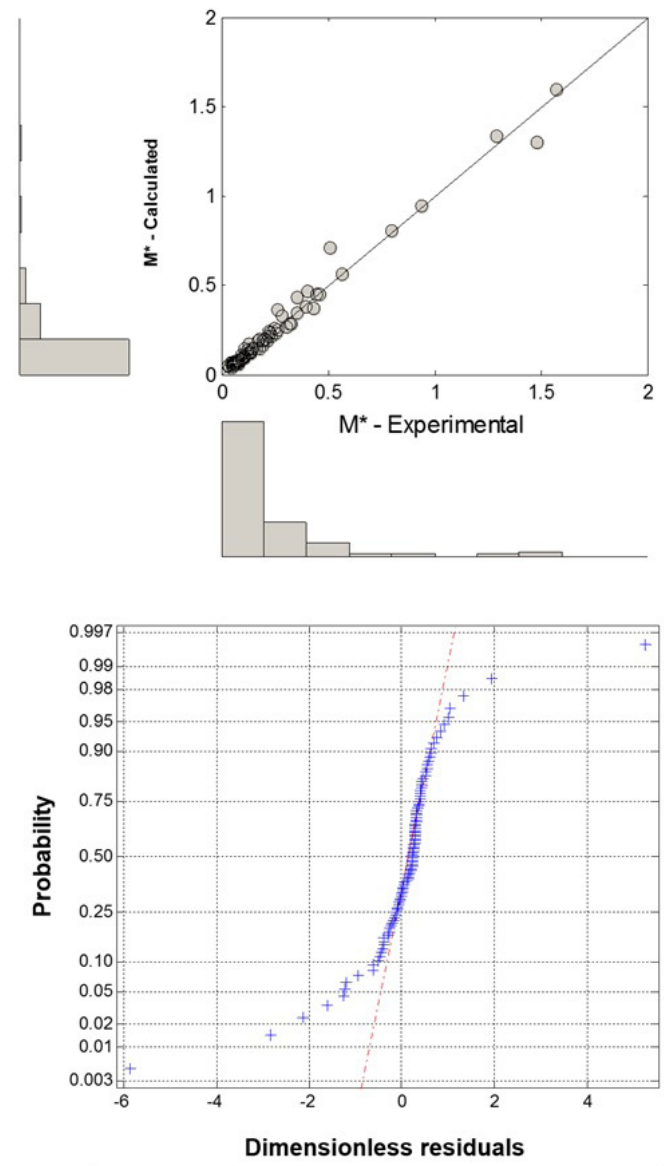

(a)

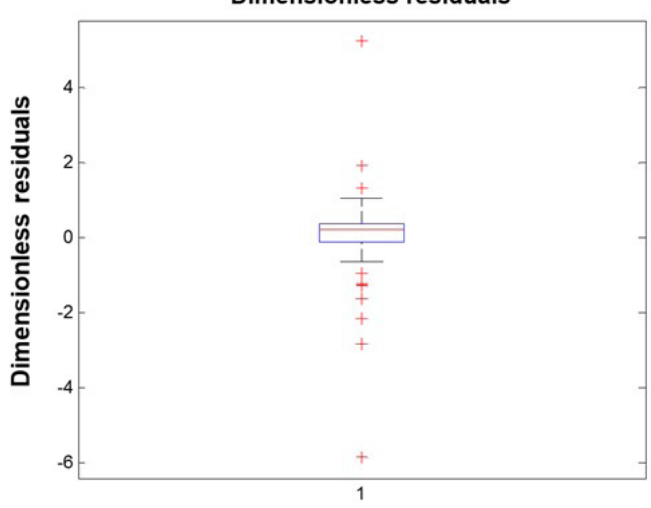

(b)

(c)

Figure 7. Analysis of Equation 6. Definitions: $\mathrm{M}^{*}=\mathrm{Mh} /\left(\mathrm{ph}^{3}\right)$, dimensionless parameter; dimensionless residuals $=\left(\mathrm{M}^{*} \mathrm{e}-\right.$ $\left.\mathrm{M}^{*} \mathrm{c}\right) / \sigma, \mathrm{M}^{*} \mathrm{e}=$ experimental data, $\mathrm{M}^{*} \mathrm{c}=$ calculated data, $\sigma=$ standard deviation. (a) Ideal line; (b) normal probability plot of the dimensionless residuals; (c) box plot for dimensionless residuals. about destabilization that would imply lateral forces (suggesting vortex shedding), or suspension during submersion (untested condition) are not included in the cited literature. The formulation obtained in the present study thus suggests instability due to impact (drag) or sliding.

\section{Adaptation and adimensionalization of the model proposed by Xia et al. (2014)}

Xia et al. (2014) modeled the critical condition of stability through a balance of drag and friction forces. Following the mentioned authors and modeling the volume of the human body as, $\operatorname{Vol}_{\text {human }}=\frac{\mathrm{m}}{\rho_{\mathrm{h}}}=\mathrm{M} * \frac{\rho}{\rho_{\mathrm{h}}} \mathrm{h}^{3}$, where $\rho_{\mathrm{h}}$ is the specific mass of the human body containing the mass " $\mathrm{m}$ ", derived from the following formulation:

$$
\mathrm{M}^{*}=\frac{\psi_{1} \mathrm{Fr}^{2} \mathrm{H}^{*} \psi_{2}}{\mathrm{H}^{* 2}-\mathrm{b}_{1} \mathrm{H}^{*}-\mathrm{a}_{1}}
$$

in which $\psi_{1}=\frac{0.5 \mathrm{C}_{\mathrm{D}} \mathrm{a}_{\mathrm{d}} \mathrm{a}_{\mathrm{p}} \mathrm{a}_{\mathrm{b}}^{2 \beta}(1+\beta)^{2}}{\mathrm{c}^{2}} ; \mathrm{c}=$ = friction coefficient (dimensionless); $\psi_{2}=2 \beta+3 ; C_{D}=$ drag coefficient, $a_{d}=$ correction factor to calculate the area corresponding to dragging; $a_{p}=$ dimensionless ratio related to the human body, specifically the relationship between average width and height; $\beta=$ empirical coefficient, normally around $1 / 7$ or $1 / 6$, the employed power law for the distribution of velocities; $\mathrm{a}_{\mathrm{b}}=$ coefficient used to adapt the distribution of velocities near the bottom and the human body (XIA et al., 2014, p. 97). The dimensionless $a_{1}$ and $b_{1}$ are present in the equation $\frac{\mathrm{Vol}_{\text {submerged }}}{\mathrm{Vol}_{\text {human }}}=\frac{\mathrm{a}_{1}}{\mathrm{H}^{*^{2}}}+\frac{\mathrm{b}_{1}}{\mathrm{H}^{*}}$. If $\mathrm{H}^{*}=1$ (which corresponds to a fully submerged human body, $\left.\mathrm{h}=\mathrm{H}_{\mathrm{h}}\right), \mathrm{Vol}_{\text {submerged }}=\mathrm{Vol}_{\text {human }}$, therefore, $a_{1}+b_{1}=1$. According to Drillis et al. (1964), $a_{1}=0.737$ and $b_{1}=0.263$ for American people, being the "anatomical mean values" used in Equation 7. This way, $\psi_{1}$ e $\psi_{2}$ were calculated furnishing Equation 8 , with $\mathrm{R}=0.94837$ and presenting a distribution of measured and calculated values which is shown in Figure 8.

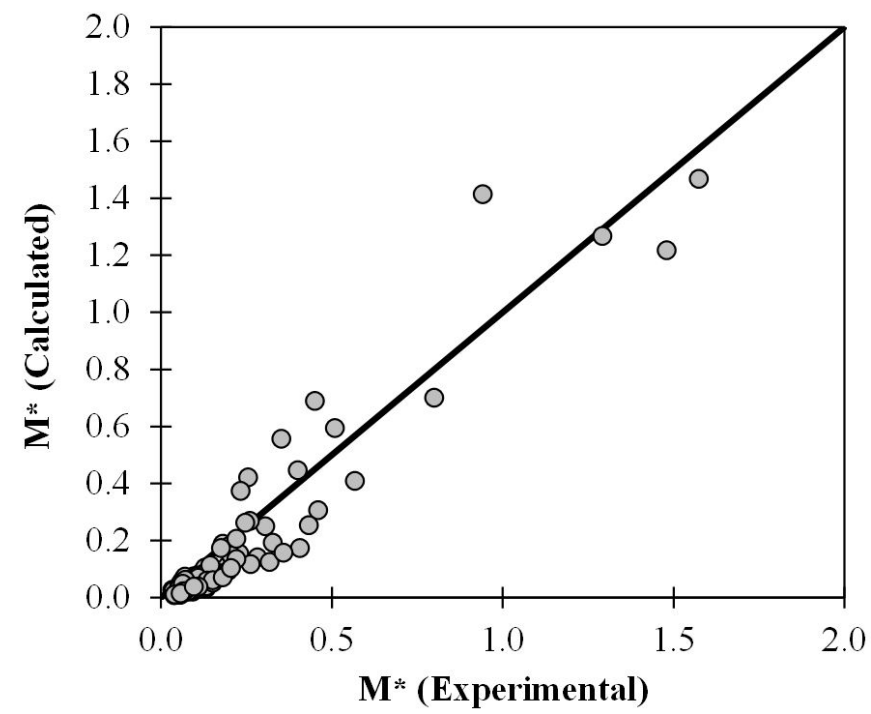

Figure 8. Comparison between measured values and calculated with Equation 8. $\mathrm{M}^{*}=\mathrm{Mh} /\left(\mathrm{ph}^{3}\right)$, dimensionless parameter. 


$$
\mathrm{M}^{*}=\frac{0.0406 \mathrm{Fr}^{2} \mathrm{H}^{* 3.81}}{\mathrm{H}^{* 2}-0.737 \mathrm{H}^{*}-0.263}
$$

Equations 6 and 8 involve the same set of dimensionless parameters: $\mathrm{M}^{*}, \mathrm{H}^{*}$ and Fr. Equation 8, however, suggests a much higher dependence of $\mathrm{M}^{*}$ on the Froude number ( $\mathrm{Fr}$ ), expressed by the exponent 2.0 instead of 0.165 . In terms of the dependence on $\mathrm{H}^{*}$, Equation 6 furnishes the exponent of 2.898, while Equation 8 can be presented also varying the exponent between $3.81\left(\mathrm{H}^{*} \rightarrow 0\right)$ and 1.81 $\left(\mathrm{H}^{*} \rightarrow \infty\right)$, with a mean value between the extremes of 2.81 . Thus, the dependency of both equations on $\mathrm{H}^{*}$ is similar, considering the mean value of the exponent. The validity of Equation 8 with the presented coefficients, is linked to the data that led to these coefficients. They derive from the proposed adjustment (for example, $\beta$ may be different from the initial proposal around $1 / 7$ to $1 / 6$, for the power law velocity profiles). Equation 8 shows that, for $\mathrm{H}^{*} \rightarrow 1, \mathrm{M}^{*} \rightarrow \infty$, suggesting the extreme case for which the instability is inevitable due to the submersion of the human body (stability would need an infinite mass).

\section{CONCLUSION}

This study evidenced important dimensionless parameters for the study of the human stability in risky water flows. Multivariate analyzes with the proposed formulation resulted in equations with high correlation coefficients and good adjustment between experimental data and calculated values. It was observed initially that the relevant dimensionless parameters, in a more complete analysis, may be composed by: $\frac{\mathrm{M}_{\mathrm{h}}}{\mathrm{\rho h}^{3}}, \mathrm{Fr}, \frac{\mathrm{H}_{\mathrm{h}}}{\mathrm{h}}, \frac{\varepsilon}{\mathrm{h}}, \mathrm{I}_{\mathrm{o}}, \frac{\mathrm{VI}}{\mathrm{h}}$, with the meanings described in the text. Successive possibilities were tested, showing that good correlations can also be obtained using only: $\frac{\mathrm{M}_{\mathrm{h}}}{\mathrm{\rho h}^{3}}, \mathrm{Fr}, \frac{\mathrm{H}_{\mathrm{h}}}{\mathrm{h}}, \frac{\varepsilon}{\mathrm{h}}, \mathrm{I}_{\mathrm{o}}$. Aiming to use literature results, a sensitivity analysis was performed, resulting as more evident dimensionless parameters the following three: $\frac{\mathrm{M}_{\mathrm{h}}}{\mathrm{ph}^{3}}, \mathrm{Fr}, \frac{\mathrm{H}_{\mathrm{h}}}{\mathrm{h}}$, possible to be
quantified with the literature data.

A second analysis was made on a previous approximate formulation of the literature, based on Newton's second law, leading to the same dimensionless parameters, $\frac{\mathrm{M}_{\mathrm{h}}}{\mathrm{\rho h}^{3}}, \mathrm{Fr}, \frac{\mathrm{H}_{\mathrm{h}}}{\mathrm{h}}$.

This formulation also correlates satisfactorily the different parameters, but presenting relatively larger errors compared to the previous empirical formulation.

The set of variables that determines the human instability in flow is quite large and rarely data is available from experiments described in the literature.

On the other hand, the correlations obtained from the analyzes as performed in this study contain the necessary elements for the quantification of human instability. These results also point the convenience of more complete experimental studies, in order to provide a larger set of the variables discussed here.

\section{ACKNOWLEDGEMENTS}

The authors thank the Research, Development and Innovation Dean's Office and the Graduate Education Dean's Office of Federal University of Bahia, Project $n^{\circ} 9169$, and CAPES, process BEX 5723/15-9.

\section{REFERENCES}

ABT, S. R.; WITTIER, R. J.; TAYLOR, A.; LOVE, D. J. Human stability in a high flood hazard. Water Resources Bulletin, v. 25, n. 4, p. 881-890, 1989. http://dx.doi.org/10.1111/j.1752-1688.1989. tb05404.x.

CHANSON, H.; BROWN, R.; XIA, J.; FALCONER, R. A.; WANG, Y.; XIAO, X. New criterion for the stability of a human body in floodwaters. Journal of Hydraulic Research, v. 52, n. 1, p. 93-104, 2015.

DRILLIS, R.; CONTINI, R.; BLUESTEIN, M. Body segment parameters. ArtificialLimbs, v. 8, n. 1, p. 44-66, 1964. PMid:14208177.

JONKMAN, S. N.; PENNING-ROWSELL, E. Human instability in flood flows. Journal of the American Water Resources Association, v. 44, n. 4, p. 1208-1218, 2008. http://dx.doi.org/10.1111/j.17521688.2008.00217.x.

KARVONEN, R. A.; HEPOJOKI, H. K.; HUHTA, H. K.; LOUHIO, A. The use of physical models in dam-break analysis. Helsinki: Helsinki University of Technology, 2000. RESCDAM Final Report.

MILANESI, L.; PILOTTI, M.; RANZI, R. A conceptual model of people's vulnerability to floods. Water Resources Research, v. 51, n. 1, p. 182-197, 2015. http://dx.doi.org/10.1002/2014WR016172.

PORTO, R. M. Hidráulica básica. São Carlos: Projeto Reenge EESC/USP, 2006.

RICHTER, J. P. Scritti letterari di Leonardo da Vinci. London: Sampson Low, Marston, Searle \& Rivington, 1883. v. 2. p. 1198. In due parti. Available from: <http://www.archive.org/details/ literaryworksofl01leonuoft $>$. Access on: 16 apr. 2008.</bok $>$

ROTAVA, J. Índices de resiliência bídrica e de perigo para gestão do risco de inundações urbanas. 2014. 130 f. Dissertation-Escola de Engenharia de São Carlos, Universidade de São Paulo, 2014.

XIA, J.; FALCONER, R. A.; WANG, Y.; XIAO, X. New criterion for the stability of a human body in floodwaters. Journal of Hydraulic Research, v. 52, n. 1, p. 93-104, 2014. http://dx.doi.org/10.1080/ 00221686.2013 .875073 .

\section{Authors contributions}

André Luiz Andrade Simões: Review of previous work, formulation of the problem, analytical investigations, and discussion of the results.

Harry Edmar Schulz: Review of previous work, formulation of the problem, analytical investigations, and discussion of the results.

Lafayette Dantas da Luz: Review of previous work, formulation of the problem, and discussion of the results. 